\title{
Geo-Risk of Cap Rock System Associated with Heterogeneous Rock Formation Consisted of Interlaying Sandstone and Shale
}

\author{
Chi-Wen $\mathrm{Yu}^{1}$, Shih-Chang Lei ${ }^{1}$, Ming-Wei Yang ${ }^{2}$, Chung-Hui Chiao ${ }^{2}$, Lian-Tong Hwang ${ }^{2}$ and Wan-Huei Yang ${ }^{2}$ \\ 1. Geotechnical Engineering Research Center, Sinotech Engineering Consultant Inc., Taipei 114, Taiwan \\ 2. CCS Pilot Project Research Team, Taiwan Power Company, Taipei 100, Taiwan
}

Received: August 24, 2015 / Accepted: September 14, 2015 / Published: November 30, 2015.

\begin{abstract}
The intra-formational seal capability was characterized by multi-layered shale baffles to act as the primary or ultimate cap system, were taken into account by homogeneous and heterogeneous models, respectively. In this study, the relevant ranges of input parameter of porosity $(20 \%-35 \%)$ and permeability $(0.0001-1,000 \mathrm{mD})$, respectively for the sandstone (storage layers) and shale (seals) have been selected, according to results of large amount of laboratory core, test from pilot 3,000 m drilling within Tai-Hsi Foreland Basin in Western Taiwan. By a comprehensive geological model, typical single well injected plume migration scenarios were stochastically simulated which covered a 20-year continuous injection (one $\mathrm{Mt}_{-} \mathrm{CO}_{2}$ per year) followed by a 1,000-year post-injection monitoring. The corresponding 2-D MHMD (maximum horizontal migration distances) of $\mathrm{CO}_{2}$ plume in the storage reservoir had been calculated with respect to heterogeneous reservoir models and their homogeneous counterparts. Moreover, the induced pressures at critical monitoring points above the injection zone were also evaluated. As a result, the shale baffles of intra-formational seal in a saline aquifers are proven to play a vital role, and capable of ensuring the safe carbon storage operation within a basin scale with a depth range about 2,100-2,500 mRT.
\end{abstract}

Key words: Pilot drilling, porosity, permeability, heterogeneous reservoir models, Western Taiwan.

\section{Introduction}

Carbon sequestration is a vital approach to combat the high $\mathrm{CO}_{2}$ emission causing the problem of global warming. It has been recommended by scientists that, preferred sequestration site can be targeted into deep saline aquifers usually found in vast sedimentary basin [1]. Additionally, it is more economical to select deep saline aquifers which are adjacent to high emission sources such as coal-fired power station in coastal area. However, enough safety must be ensured by the existence of a competent cap rock system to reduce the geo-sequestration risk by forming a leakage pathway to a minimum.

In many empirical cases, cap rock system associated

Corresponding author: Chi-Wen Yu, deputy director, research field: geotechnical engineering. E-mail: yu1014@sinotech.org.tw. with interlaying sandstone with shale is often encountered in shallow sedimentary basins around the world. Unlike a well-defined thick layered cap, rock system possessing a perfect laterally extension, an intra-formational seal type of cap rock system characterized by frequently occurred intervening thin shale, or baffles, within the main sandstone reservoirs are regarded as the realistic seal mechanism in most cases.

Geotechnical Engineering Research Center of Sinotech Engineering Consultants, Inc. (abbr. as Sinotech Inc.) had been constantly commissioned by Taiwan Power Company (Tai-Power) since 2009 to investigate the Tai-Hsi Basin through on-site seismic survey [2-4] and deep drilling around a candidate site located in Chang-Hua coastal industrial park in Central Taiwan. A 3,000 $\mathrm{m}$ deep pilot drilling (TPCS-M1 or 
M-1 well) was launched in July, 2012 and concluded in November, 2013 [5-7].

The above-mentioned studies had confirmed local stratigraphic sequence and the top depth (by mRT) and thickness (m) of major Formation, and obtained more than $1,390 \mathrm{~m}$ long cores from depth of 1,505 $\mathrm{mRT}$ to 3,005 mRT. These cores were sampled and extensively examined by lots of laboratory analysis and testing. According to some preliminary and/or comprehensive results, it is confirmed that, many target sandstone rich formations or deep saline reservoirs within Tai-Hsi Basin are very suitable $[8,9]$ for developing geological storage [3, 5-7].

Table 1 shows the on-site stratigraphic sequence and the thickness $(\mathrm{m})$ of all the major formations revealed in the recently completed M-1 well. The large amount of drilled cores had shown that, the lithological units were prevailed by interlaying sandstone with shale, and indicated these rocks had been deposited in a shallow marine environment.

\section{Geological Background}

\subsection{Area of Interest}

As shown in Fig. 1, some $30 \mathrm{~km}$ radial distance around the drilling site of M-1 well has been allocated [2,6] as an area of interest for developing the geological model on purpose of a $\mathrm{CO}_{2}$ sequestration. It can be noted, some exploratory wells done by CPC (Taiwan Petroleum Company) are sparsely distributed around the highlighted area, and also a coal-fired power plant located $15 \mathrm{~km}$ in the north of M-1 drilling site. The area of interest is located inside a Geological Subzone of Taiwan, locally named as Tai-Hsi Basin [10]. This relative young basin is basically a foreland basin produced by an orogenic activity starting from Early Pliocene. The candidate site happened to be part of a foreland bulge which lied within the southern flank of the foreland basin. The rock formations below the CS (Chin-Shui) Formation (Table 1) may have been deposited by sedimentation originated from the mainland China, during the time before Taiwan islands were lifted up in the latest orogeny. On the contrary, rock formation younger than Chin-Shui formation is believed to be derived from the ancient Taiwan Central Range in the east side during the orogenic episode.

\subsection{Regional Geological Model}

The geological profile shown in Fig. 2 illustrates the off-shore and on-shore regional geological model with seismic data. This profile lines in W-E direction, and runs roughly normal to the coastal line as shown in Fig. 2 and across the 3,000 $\mathrm{m}$ drilling site.

Based on evidence of different scale seismic surveys, it had been noted that, the thickness of each

Table 1 Stratigraphic sequence and the thickness of major formations revealed in M-1 well.

\begin{tabular}{llllll}
\hline $\begin{array}{l}\text { Regional geological units } \\
\text { (formation/member) }\end{array}$ & Abbr. formation name & $\begin{array}{l}\text { NN zoning by } \\
\text { core analysis }\end{array}$ & $\begin{array}{l}\text { Drilling } \\
\text { interval }\end{array}$ & $\begin{array}{l}\text { Conceptual model } \\
\text { after 3,000 m drilling }\end{array}$ & $\begin{array}{l}\text { Reservoir } \\
\text { potential }\end{array}$ \\
\hline 0-17 Ma & & & mRT & Formation thickness (m) & Ultimate cap \\
\hline Recent sediments & Overburden & - & G.L.-841 & 841 & Primary cap R-1 \\
Tou-ko-shan & TKS (Tou-ko-shan) & NN-19 & $841-1,717$ & 876 & R-1 \\
Cho-lan & CL (Cho-lan) & NN-19a & $1,717-2,135$ & 418 & Primary cap R-2 \\
Chin-shui & CS (Chin-shui) & NN-18 & $2,135-2,295$ & 160 & R-2 \\
Kei-chu-lin/Yutengping & KCL (Kei-chu-lin) & NN-17 & $2,295-2,450$ & 155 & - \\
Kei-chu-lin/Shihliufeng & Absent & NN-17 & Absent & Unconformity & - \\
Kei-chu-lin/Kuantaoshan & Absent & NN-17 & Absent & Unconformity & - \\
Nan-chung/Shangfuchi & Absent & NN-16 & Absent & Unconformity & - \\
Nan-chung/Tunkeng & Absent & NN-16 & Absent & Unconformity & R-2 \\
Kuan-yin-shan & KYS (Kuan-yin-shan) & NN-13 16 & $2,450-2,608$ & 158 & Primary cap R-3 \\
Ta-lu & TL (Ta-lu) & NN-5,6 & $2,608-2,800$ & 192 & R-3 \\
Pei-liao & PL (Pei-liao) & NN-3,4 & $2,800-3,005$ & 205 & \\
\hline
\end{tabular}


Consisted of Interlaying Sandstone and Shale

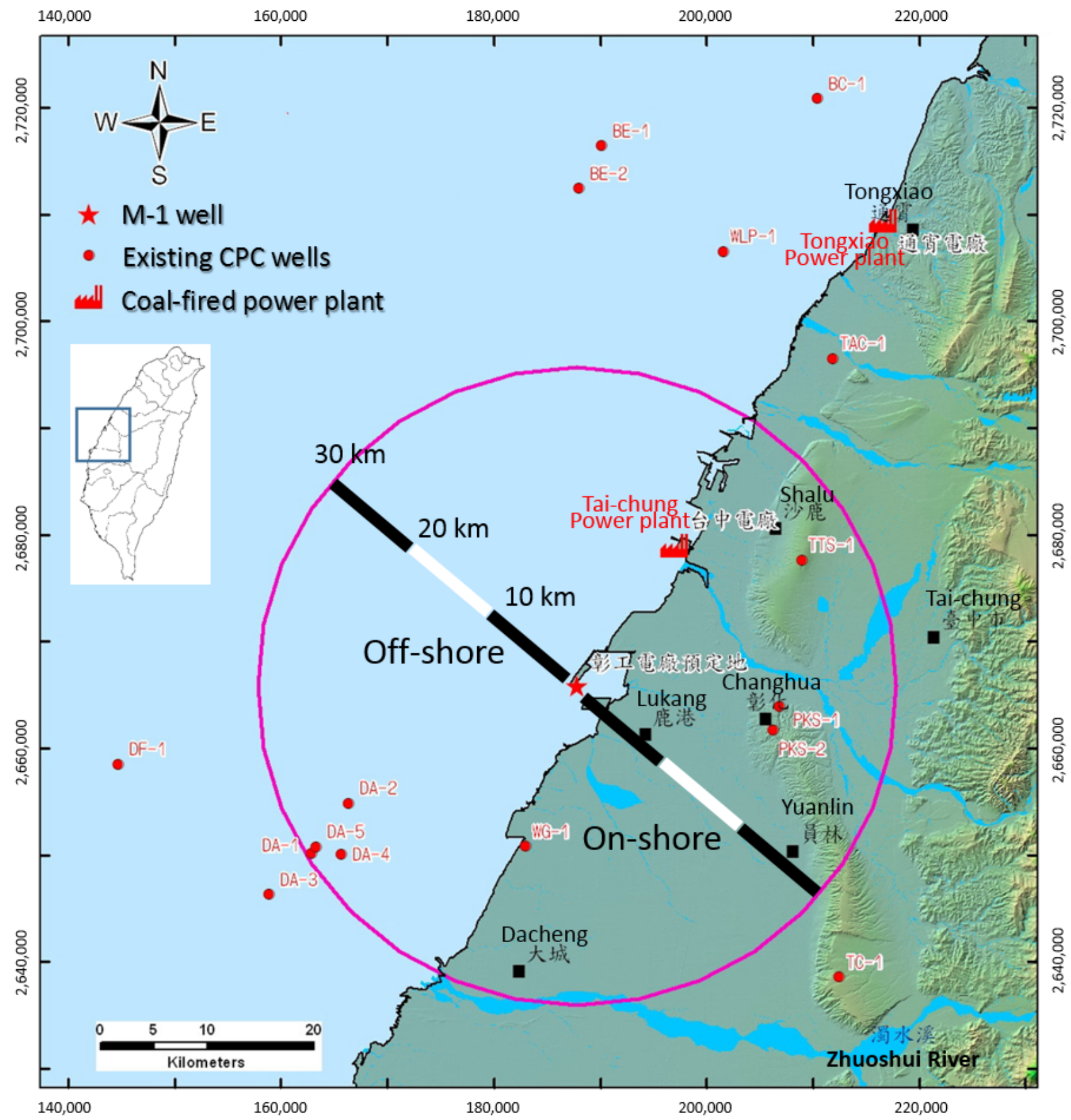

Fig. 1 Area of interest of the sequestration plan (with M-1 well in the center).

interested formation is decreasing towards to the west from the inland to offshore, with a dip angle approximately $3-5^{\circ}$ dipping gently to the east. No active fault has been found in this area of interest, and only very limited seismic activity exceeding magnitude 3 has been recorded so far.

To ensure the safety and security of carbon storage, some screening criteria had been preliminarily chosen to redefine the area of interest, as shown below:

(1) cap rock thickness up to $30 \mathrm{~m}$;

(2) at least $5 \mathrm{~km}$ away from the suspicious active fault;

(3) storage depth to be greater than $800 \mathrm{~m}$;

(4) injection operation depth to be less than $3,000 \mathrm{~m}$. 


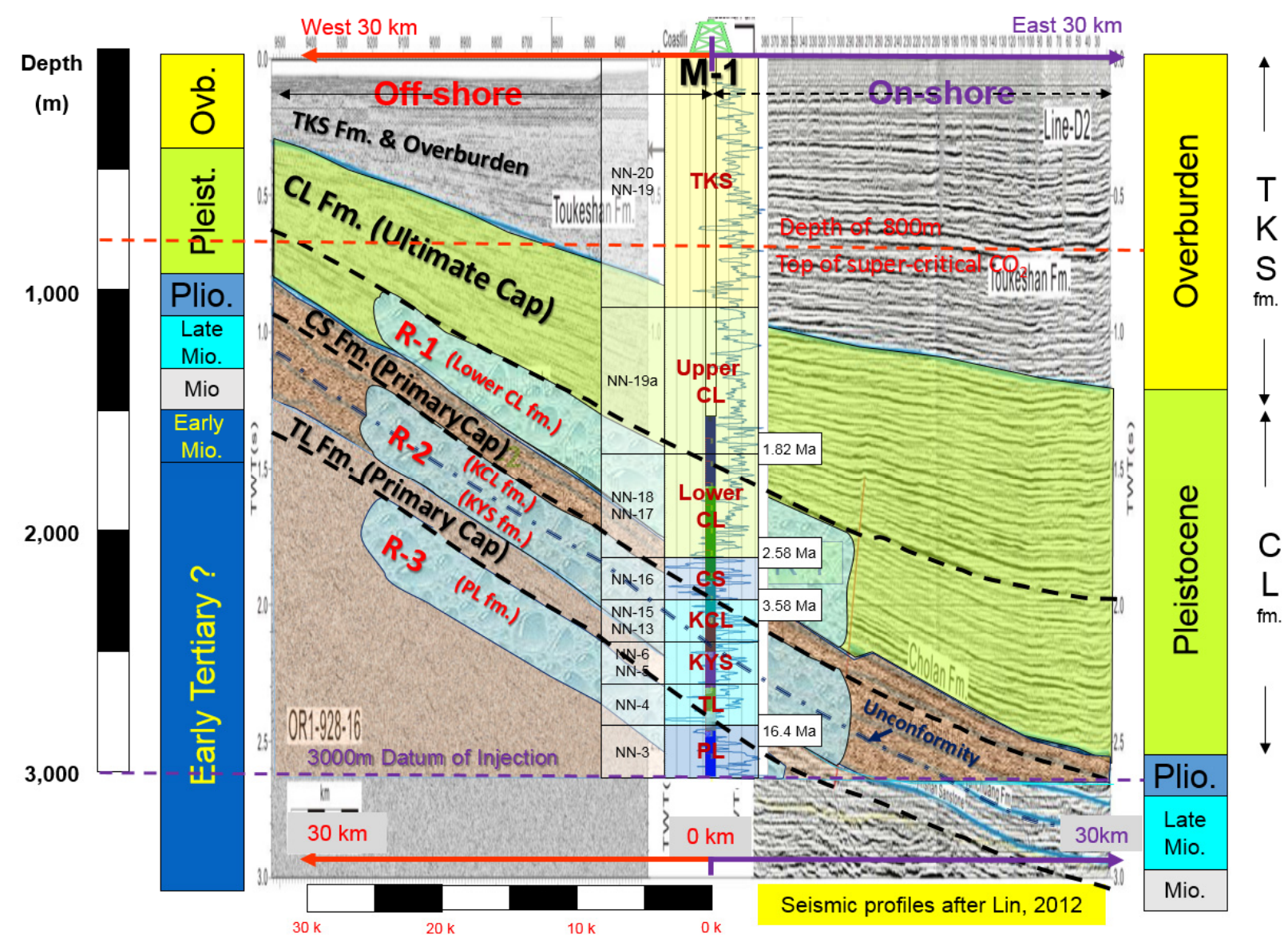

Fig. 2 Geological profile across the western coast of Taiwan (note: M-1 well in the center).

Fig. 3 shows the 3-D geological model and the realistic area of interest which meets the sandstone reservoir selection criteria. The 3,000 m pilot drilling also help to identify a multi-layered reservoir system underneath the areal scope of the area of interest. Consequently, three high potential storage systems were identified, namely R-1, R-2 and R-3, from top to bottom. Their effective storage capacities had been evaluated as 4.9, 6.3 and 2.5 giga-ton, respectively. Well logging data (by Schlumberger) obtained from the M-1 well were taken as a crucial tool to examine the adequacy of selected reservoir. Fig. 4 shows the well logging porosity data of multi-layered reservoir system from $1,500 \mathrm{~m}$ below ground, down to the 3,000 m of M-1 well.

\subsection{Reservoir Rock Injectivity}

Roughly seven major geological formations (Table 1) can be identified by $3,000 \mathrm{~m}$ drilling as mapped with the regional sedimentary geology. All of them are sedimentary rocks originated at a shallow marine environment, and interpreted as litho-facies belonging to shoreface, inter-tidal zone, upper to lower offshores etc. This candidate sequestration site is thus believed to adjacent to a passive continental shelf in Early Pleistocene to Middle Miocene. Alternation of sandstone, siltstone and mudstone (or shale) encompassed the basic lithological units all the way down to $3,000 \mathrm{~m}$ deep.

Statistically speaking, no massive sandstone or mudstone layers with thickness exceeding $15 \mathrm{~m}$ can be logged, and most often the thickness of all mappable layers or lithological units are within several meters only, as can be grouped as below:

- sandstone interbedded with shale: laminated layers, mini-meter to centi-meter thick; 
- sandstone intercalated with shale: thin layers, centi-meter to meters thick;

- massive sandstone: several meters to tens of meters thick;

- massive shale: several meters to tens of meters thick.

$\mathrm{CO} 2 \mathrm{CRC}\left(\mathrm{CO}_{2}\right.$ Cooperative Research Centres [11]) defined reservoir rock injectivity (or injection rate) as a function of (1) wellbore contact area, (2) injection pressure, and (3) rock permeability. Among them, the rock permeability is the prime factor which can be used to examine the injectivity before the in-situ test comes up as a real. From core scale test, the absolute permeability of most sandstones and some siltstone are

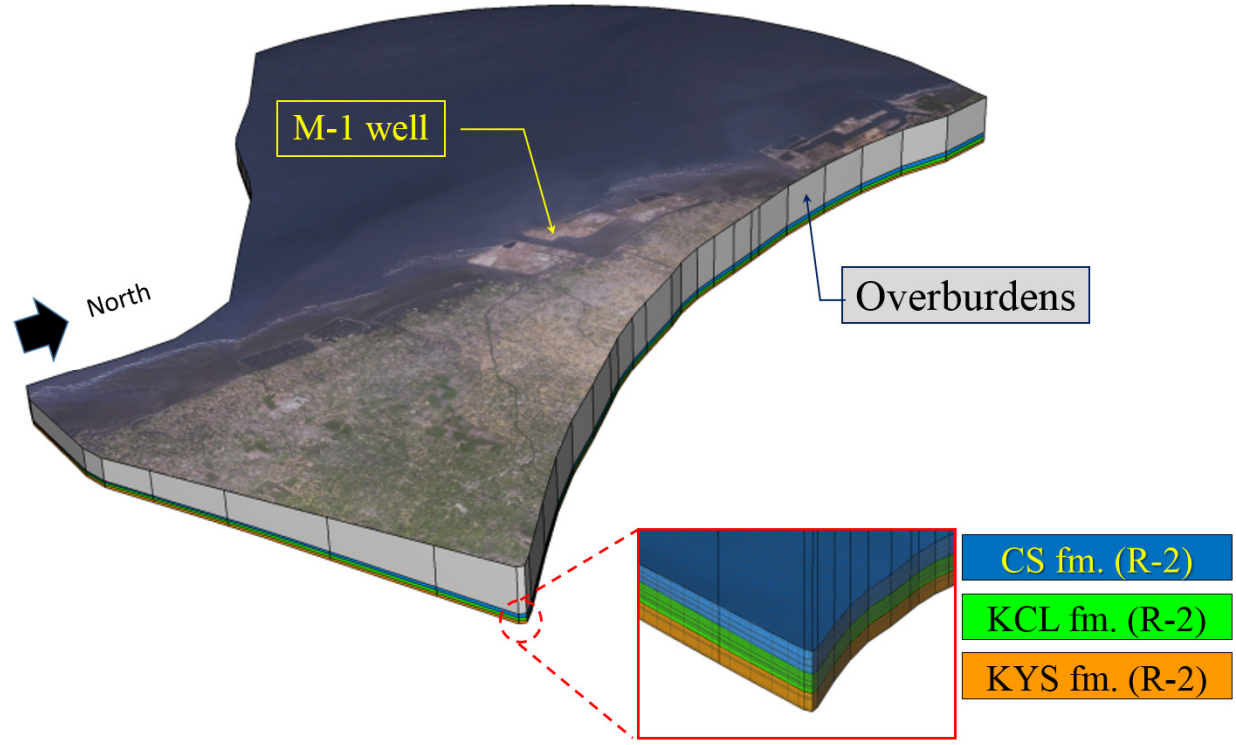

Fig. 3 Realistic area of interest reference to R-2 by site selection criteria.

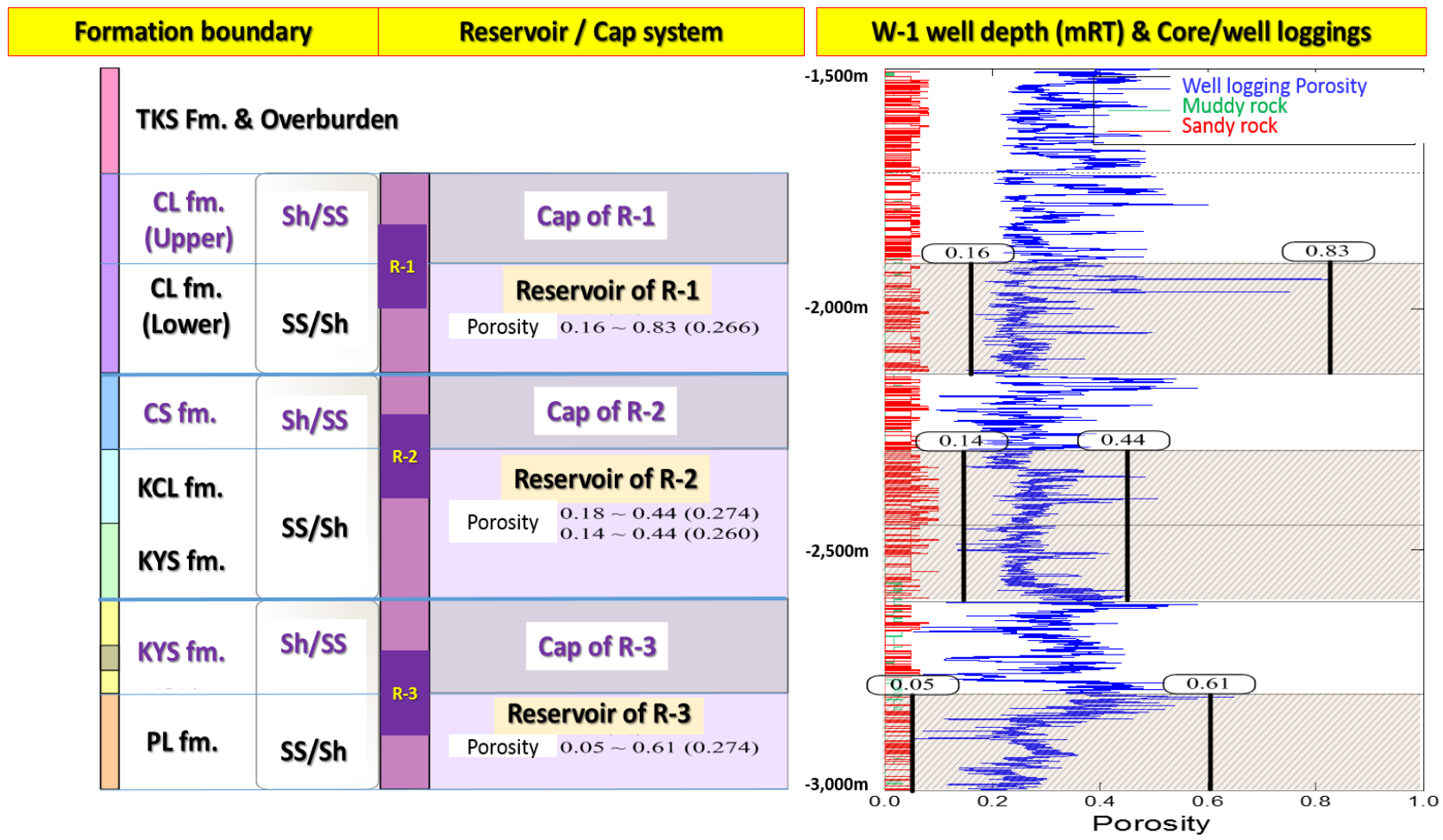

Fig. 4 Vertical distributions of the multi-layered reservoir systems of R-1, R-2 and R-3. 
in range of 1-1,000 $\mathrm{mD}$ (Mili-Darcy), while most of the mudstones and some siltstone are in range of 0.00001-1 mD. Relative permeability test also shows the injectivity of most tested sandstone meet the general requirements of empirical values.

Fig. 5 shows the statistics of neutron porosity values from the in-situ well logging for four major reservoirs, respectively in R-1, R-2 and R-3. Some of the porosity values may not be realistic when they are of values over 0.5 . Such a discrepancy may be representing an overcut of the wellbore and/or drilling mud contamination. Nevertheless, the histograms shown in Fig. 5 can give a good reference on the rock porosity values which are mostly in the range of $0.15-0.45$. Rock permeability can be predicted by establishing an empirical relationship in between porosity and permeability as long as enough test data are available.

\subsection{Cap Rock Seal Potential}

Above the top most R-1 reservoir (2,295-2,450 mRT)

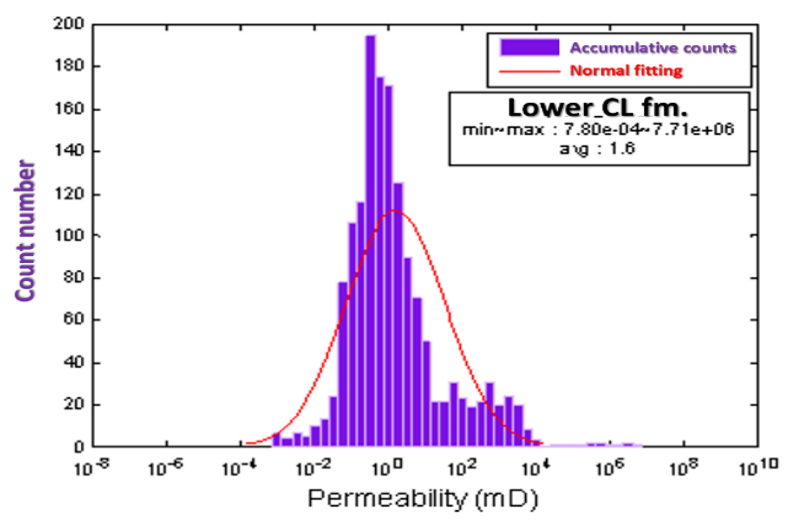

(a) (R-1) in CL formation

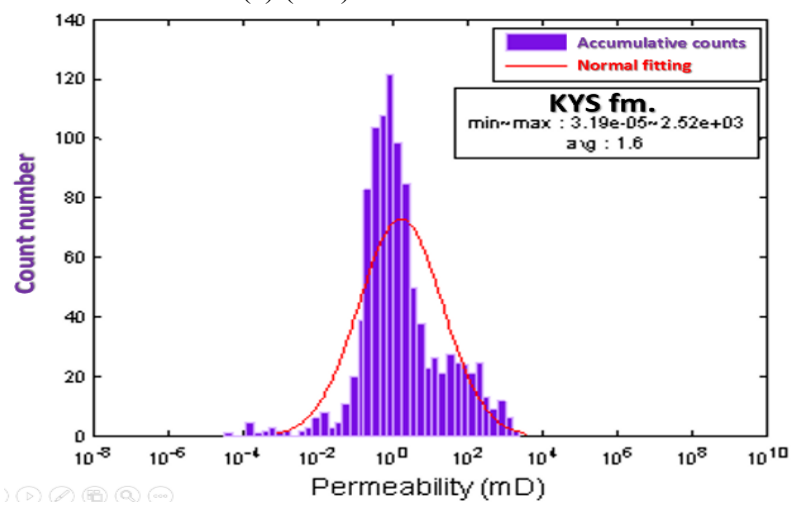

(c) (R-2) in KYS formation and all the way up to the ground surface, almost 2,000 m thick of overlying rock can be expected as an ultimate or competent cap system. This can be served as the final barriers for securing unwanted leakage path of deep sequestered $\mathrm{CO}_{2}$, despite no distinct, massive shale formation were found to be outstanding and suitable for a good primary seal.

Table 2 summarizes the cap rock seal potential underneath the area of interest. Here the cap rock seal potential was examined according to the large amount of typical core test results. The potential can be justified by three criteria recommended by IEA (2011) [8]. These criteria selected for site specific reservoir systems are respectively shown below:

- seal capacity: max. $\mathrm{CO}_{2}$ column that can be retained by cap rock;

- seal geometry: thickness and lateral extent of the cap rock;

- seal integrity: geo-mechanical properties of cap rock.

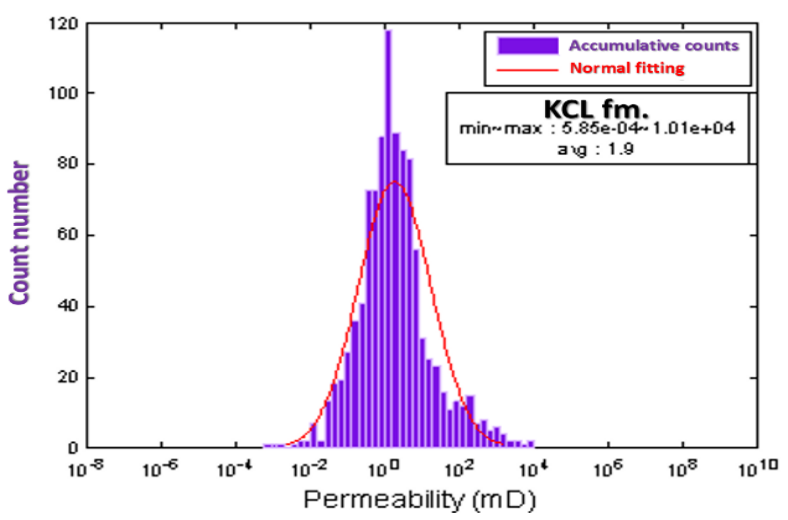

(b) (R-2) in KCL formation

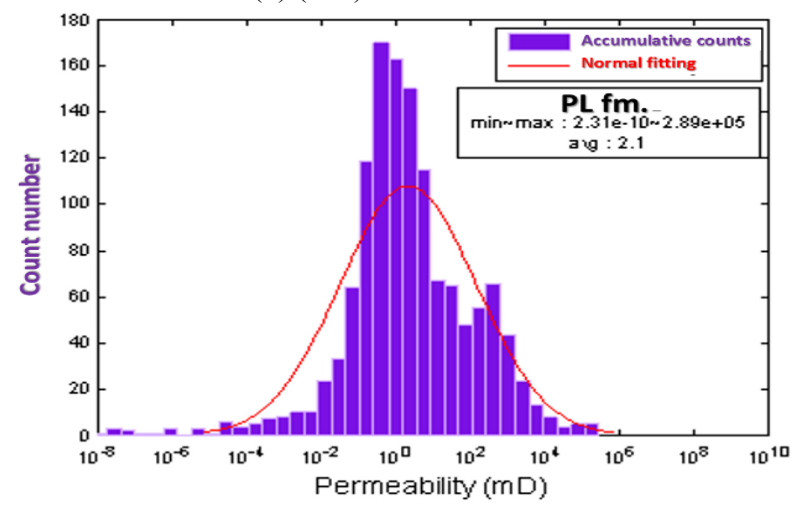

(d) (R-3) in PL formation

Fig. 5 Neutron porosity from the in-situ well logging for four major reservoirs. 
Table 2 Cap rock seal potential within area of interest.

\begin{tabular}{|c|c|c|c|}
\hline $\begin{array}{l}\text { Cap rock } \\
\text { seal potential } \\
\end{array}$ & R-1 cap & R-2 cap & R-3 cap \\
\hline \multirow{2}{*}{ (1) Seal capacity } & $66-152 \mathrm{~m}^{*}$ & $583 \mathrm{~m}^{*}$ & $967 \mathrm{~m}^{*}$ \\
\hline & $\bigcirc$ & ○ & $\odot$ \\
\hline (2) Seal geometry & $\begin{array}{l}\text { Thickness } 218 \mathrm{~m} \\
\text { Lateral extension fair to good } \\
\odot\end{array}$ & $\begin{array}{l}\text { Thickness } 160 \mathrm{~m} \\
\text { Lateral extension good } \\
\text { - }\end{array}$ & $\begin{array}{l}\text { Thickness } 192 \mathrm{~m} \\
\text { Lateral extension good } \\
\text { ○ }\end{array}$ \\
\hline (3) Seal integrity & $\begin{array}{l}\text { Sandstone intercalated with shale } \\
\end{array}$ & $\begin{array}{l}\text { Sandstone intercalated with shale } \\
\odot\end{array}$ & $\begin{array}{l}\text { Sandstone interbedded with shale } \\
\odot\end{array}$ \\
\hline
\end{tabular}

Max $\mathrm{CO}_{2}$ column height calculated from MICP; $\bigcirc$ may need to be further confirmed or verified; $\odot$ moderate condition; $\odot$ good condition.

Maximum $\mathrm{CO}_{2}$ column heights calculated from MICP (mercury injection capillary pressure [12]) data for most tested cores, showed quite high seal capacities can be expected for the most mudstone (shale) and some siltstone. Although most distinct and continuous massive shale can only be found in depth between 2,135-2,146 mRT, with a thickness of $11 \mathrm{~m}$ located on the top of CS formation. Nevertheless, numerous pairs of thin sandstone and shale from $3,000 \mathrm{~m}$ deep up to the ground surface are generally laterally extensive and would become relative competent barrier to hindering vertical $\mathrm{CO}_{2}$ flow.

As a consequence, the intra-formation seal $[8,13,14]$ or multilayered cap rock system would then be expected to ensure the safety and security of $\mathrm{CO}_{2}$ storage in such a geological condition. However, an uncertain scenario analysis should be carried out with still insufficient geological data as depicted in the following section.

\section{Scenario Analysis and Numerical Modelling}

\subsection{Define Homogeneous and Heterogeneous Models}

Horizontal $\mathrm{CO}_{2}$ migration distances for the candidate site during $\mathrm{CO}_{2}$ inject are of the prime importance for checking the safety of carbon storage. Here, homogeneous and heterogeneous site models were both taken into account as shown in Fig. 6. In both models, only the R-2 reservoir was considered, and the injection zones were pre-determined by an injection interval length of $155 \mathrm{~m}$, equivalent to the entire drilling thickness of KCL formation
(2,295-2,450 mRT). The injection wells are assumed to be located in the existing M-1 well. Table 2 shows the geological models of homogeneous and heterogeneous cases respectively in this study.

In the homogeneous model, the porosity of the injection zone is a uniform value of $35 \%$ compared with a cap rock (e.g., CL formation) porosity of $20 \%$. In correlation, the permeability of the injection zone is a uniform value of $59 \mathrm{mD}$, compared with a cap rock permeability of $0.0277 \mathrm{mD}$. These values represent a nominal tested data range of large amount of core test.

In the heterogeneous model, the rough lithological units of inter-bedding sandstone and shale, according to the findings of drilling, are used instead of Major Geological formation, e.g., KCL formation, to reflect the more realistic multilayered cap rock system. In general, a porosity value of $35 \%$ and a permeability of $59 \mathrm{mD}$ are used for all the sandstone layers, while a porosity value of $20 \%$ and a permeability of $0.0277 \mathrm{mD}$ are used for all the shale. Shale rocks are regarded as the layers which can provide a primary seal or act as the baffles in the intra-formational seal condition.

\subsection{Scenario Analysis for Homogeneous and Heterogeneous Models}

Reservoir simulator TOUGH2 with ECO2N module [15] had been used to conduct uncertain scenario analysis. Two kinds of geological model had been considered to emphasis the difference in horizontal $\mathrm{CO}_{2}$ migration distances between a homogeneous and a heterogeneous model. Numerical 
simulation was carried out in a 2-D manners where the grid size of $200 \mathrm{~m}$ (in lateral of $\mathrm{X}$ direction) $\times 5 \mathrm{~m}$ (in vertical or $\mathrm{Y}$ direction) had been used for both models.

Fig. 7 shows the $\mathrm{CO}_{2}$ migration results in the scenario analysis for both models after 20 year of injection plus 1,000 years of monitoring. The $\mathrm{CO}_{2}$ injection amount of the simulation is set at one million metric tons per year per well, and injection operation is continuously done with a duration of 20 years. The post-injection monitoring is designed up to 1,000-year period. The MHMD (maximum horizontal migration distance) for both models are towards the west due to the eastward gentle dipping angle within the geological model. At the end of the monitoring, MHMD is reaching $10 \mathrm{~km}$ for the homogeneous case, while the case in the heterogeneous model shows a much reduced MHMD of $3.1 \mathrm{~km}$.

It can be noted that, in the case of heterogeneous

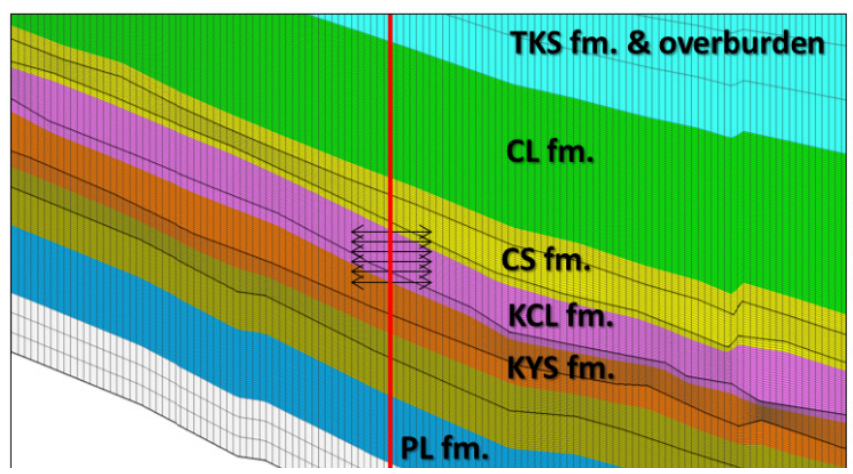

(a) Homogeneous model (layering by major geological formation) model, more components of injected $\mathrm{CO}_{2}$ can move upward and penetrate into the lower part of cap rock (e.g., CL formation) and ultimately capped by a single shale unit with good thickness of lateral extension. This should be the quite typical situation in an intra-formation seal mechanism where a multi-layered primary seal are existent or an ultimate seal act as a barrier, which can prevent further vertical $\mathrm{CO}_{2}$ movement in the long run. The thickness of such ultimate seal does not have to be very thick because most of mobile $\mathrm{CO}_{2}$ has been residually trapped in the rock void through their upward journey.

\subsection{Scenario Analysis with Uncertain Parameters in the Heterogeneous Model}

The migratory analysis for the heterogeneous model shown in Fig. 7 is regarded as a quite realistic scenario for the storage in the candidate deep saline aquifer

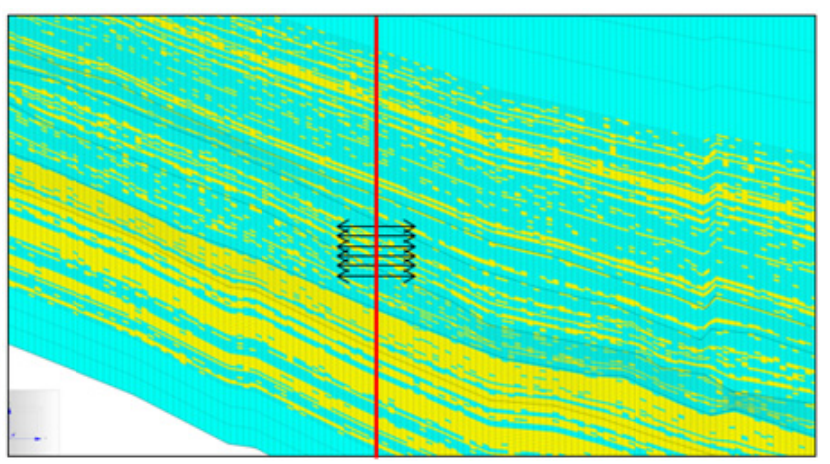

(b) Heterogeneous model (shale baffles shown in yellow color)

Fig. 6 Geological profiles for homogeneous and heterogeneous models for R-2 sequestration.

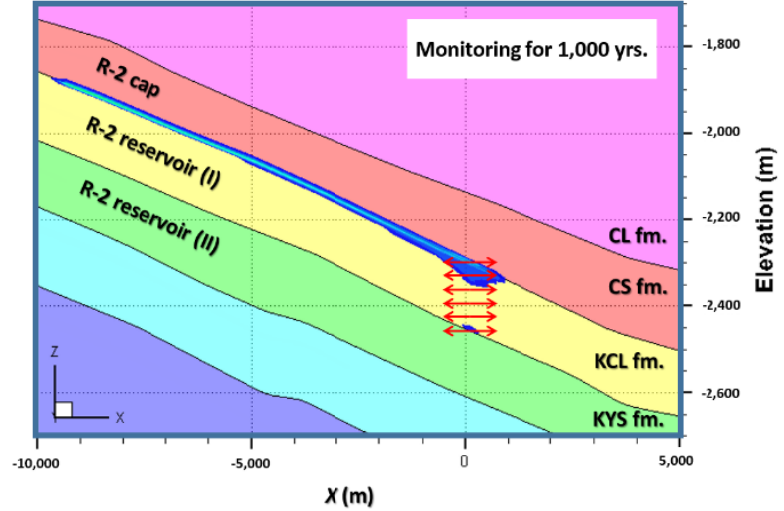

(a) Case of homogeneous model (R-2)

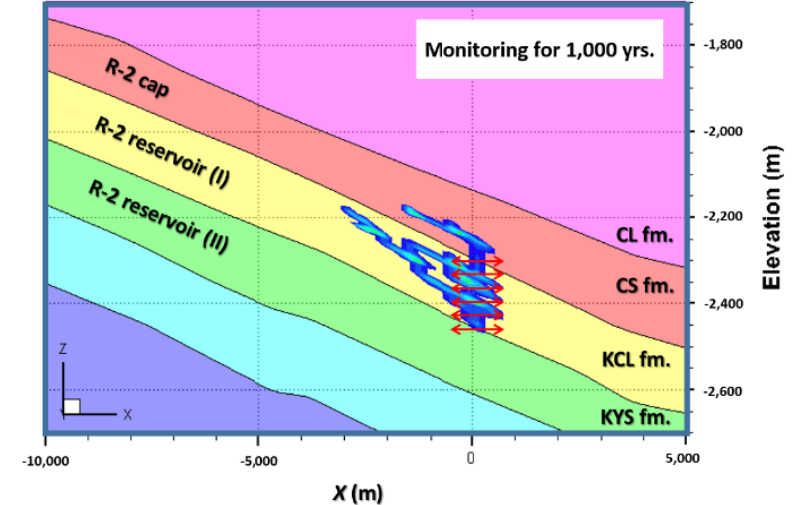

(b) Case of heterogeneous model (R-2)

Fig. 7 MHMD (maximum horizontal migration distance) results in scenario analysis showing fates of injected $\mathrm{CO}_{2}$ plume at 1,020 year. 


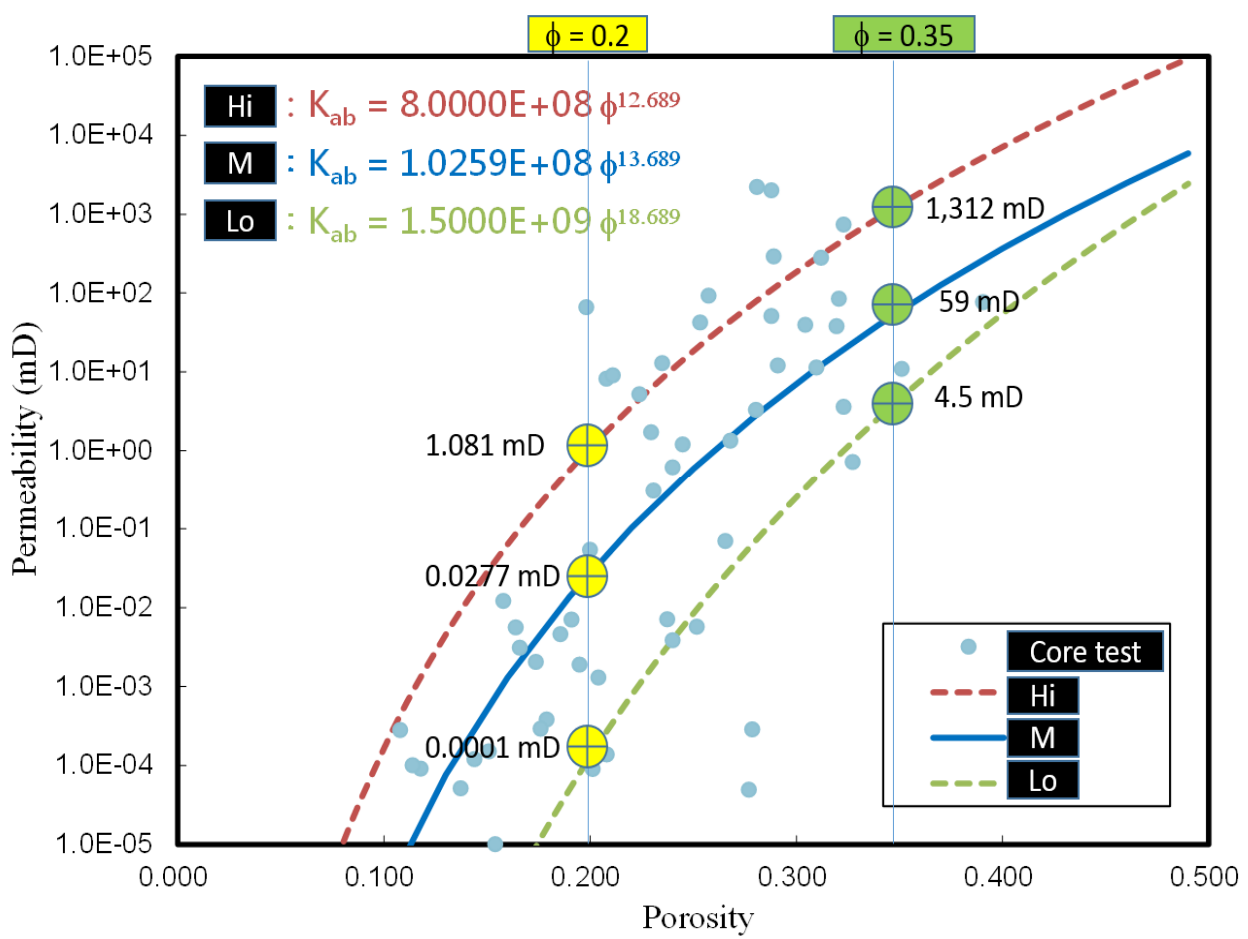

Fig. 8 Empirical relationship between porosity and permeability based on laboratory core test.

within Tai-Hsi Basin. However, a probabilistic study is necessary to check the uncertainly when the assumed nominal parameters might be changed. Fig. 8 shows the relationship of porosity and permeability from the results of laboratory core test. The upper and lower bound of permeability values can be defined at a porosity values targeted at $20 \%$ and $35 \%$, in addition to the nominal permeability values. Consequently, overall nine scenario cases can be taken into account to cover all of the input uncertainties, and reflect almost all possibility of porosity and permeability variations.

Table 3 shows the input data and the results of MHMD ( $\mathrm{m}$ ) in the scenario analysis considering all the nine cases with the heterogeneous model. With a maximum permeability of sandstone $(1,312 \mathrm{mD})$, coupled with minimum permeability of shale (0.0277-0.00001 $\mathrm{mD}$ ), the most credible MHMD values can reach to $4.7 \mathrm{~km}$ (Case 2, and Case 3), about $1.6 \mathrm{~km}$ more extensive compared with a nominal values of $3.1 \mathrm{~km}$ (Case 5). Accordingly, Fig. 9 illustrates the MHMD (m) evolution with time duration up to 1,020 years for all the cases. Except the case of homogeneous model, all the nine cases of heterogeneous model showed the MHMD (m) will substantially come to stable around 100 years later gauging from initial injection. In the case of homogeneous model, in contrast, the continuing horizontal moving of injected plume can last for hundreds of year without apparent stabilization.

In addition to the MHMD, the induced pressures inside the cap rock formation at a critical monitoring point above the injection zone $(2,162 \mathrm{mRT})$ are evaluated and acted as a pressure control tool. Fig. 10 shows the induced pressures calculated for the nine scenario cases, respectively using heterogeneous model. As a rule of thumb, Case 1 to Case 3 is grouped as high pervious case with which the MHMD is high and hence the induced pressure tend to be low $(<1,000 \mathrm{kPa})$. On the contrary, Case 7 to Case 9 can be grouped as low pervious case with lower MHMD, but higher induced pressure reaching 10,000 $\mathrm{kPa}$ (e.g., Case 9). Case 4 to Case 6 are regarded as a moderate case which possessed moderate induced pressure. 
Table 3 Parameters values of the main parameters of heterogeneous analysis.

\begin{tabular}{|c|c|c|c|c|c|}
\hline $\begin{array}{l}\text { Scenario } \\
\text { case No. }\end{array}$ & $\begin{array}{l}\text { Main } \\
\text { litho-units }\end{array}$ & $\begin{array}{l}\text { Input } \\
\text { porosity }(\%)\end{array}$ & $\begin{array}{l}\text { Input } \\
\text { permeability }(\mathrm{mD})\end{array}$ & $\begin{array}{l}\text { MHMD }(\mathrm{m}) \\
\text { after } 20 \text { year of injection }\end{array}$ & $\begin{array}{l}\text { MHMD }(\mathrm{m}) \text { after } 1,000 \\
\text { years of monitoring }\end{array}$ \\
\hline \multirow{2}{*}{1} & Sandstone & 35 & 1,312 & \multirow{2}{*}{$\approx 1.9 \mathrm{~km}$} & \multirow{2}{*}{$\approx 3.3 \mathrm{~km}$} \\
\hline & Shale & 20 & 1.081 & & \\
\hline \multirow{2}{*}{2} & Sandstone & 35 & 1,312 & \multirow{2}{*}{$\approx 2.3 \mathrm{~km}$} & \multirow{2}{*}{$\approx 4.7 \mathrm{~km}$} \\
\hline & Shale & 20 & 0.0277 & & \\
\hline \multirow{2}{*}{3} & Sandstone & 35 & 1,312 & \multirow{2}{*}{$\approx 2.3 \mathrm{~km}$} & \multirow{2}{*}{$\approx 4.7 \mathrm{~km}$} \\
\hline & Shale & 20 & 0.0001 & & \\
\hline \multirow{2}{*}{4} & Sandstone & 35 & 59 & \multirow{2}{*}{$\approx 0.7 \mathrm{~km}$} & \multirow{2}{*}{$\approx 2.1 \mathrm{~km}$} \\
\hline & Shale & 20 & 1.081 & & \\
\hline \multirow{2}{*}{$5^{*}$} & Sandstone & 35 & 59 & \multirow{2}{*}{$\approx 0.7 \mathrm{~km}$} & \multirow{2}{*}{$\approx 3.1 \mathrm{~km}$} \\
\hline & Shale & 20 & 0.0277 & & \\
\hline \multirow{2}{*}{6} & Sandstone & 35 & 59 & \multirow{2}{*}{$\approx 0.7 \mathrm{~km}$} & \multirow{2}{*}{$\approx 3.3 \mathrm{~km}$} \\
\hline & Shale & 20 & 0.0001 & & \\
\hline \multirow{2}{*}{7} & Sandstone & 35 & 4.5 & \multirow{2}{*}{$\approx 0.3 \mathrm{~km}$} & \multirow{2}{*}{$<1 \mathrm{~km}$} \\
\hline & Shale & 20 & 1.081 & & \\
\hline \multirow{2}{*}{8} & Sandstone & 35 & 4.5 & \multirow{2}{*}{$\approx 0.5 \mathrm{~km}$} & \multirow{2}{*}{$<1 \mathrm{~km}$} \\
\hline & Shale & 20 & 0.0277 & & \\
\hline \multirow{2}{*}{9} & Sandstone & 35 & 4.5 & \multirow{2}{*}{$\approx 0.5 \mathrm{~km}$} & \multirow{2}{*}{$<1 \mathrm{~km}$} \\
\hline & Shale & 20 & 0.0001 & & \\
\hline
\end{tabular}

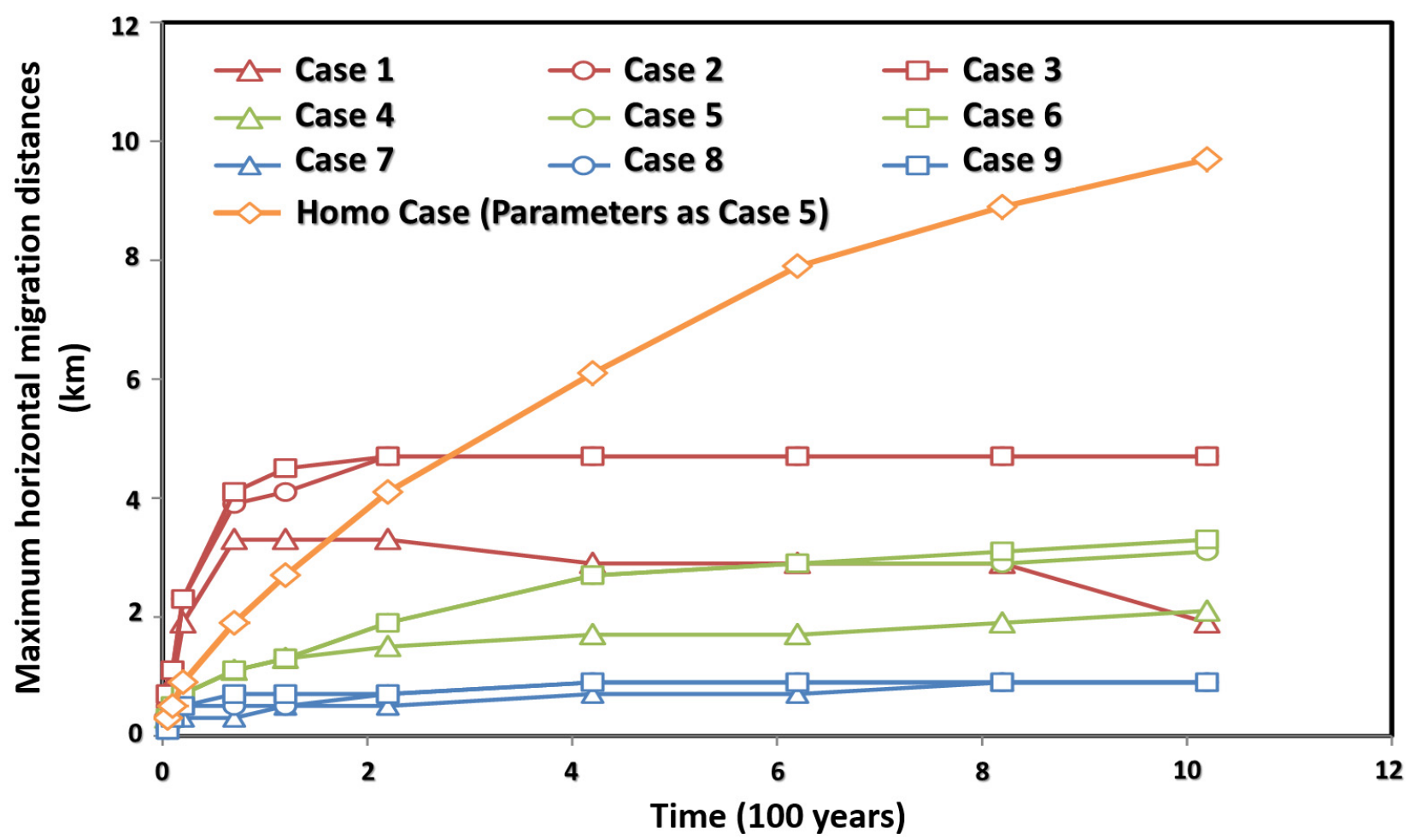

Fig. 9 Comparisons of the maximum travel distances of plume migration up to 1,020 year of (red color represents high permeability; green color represents medium permeability; blue color represents low permeability). 


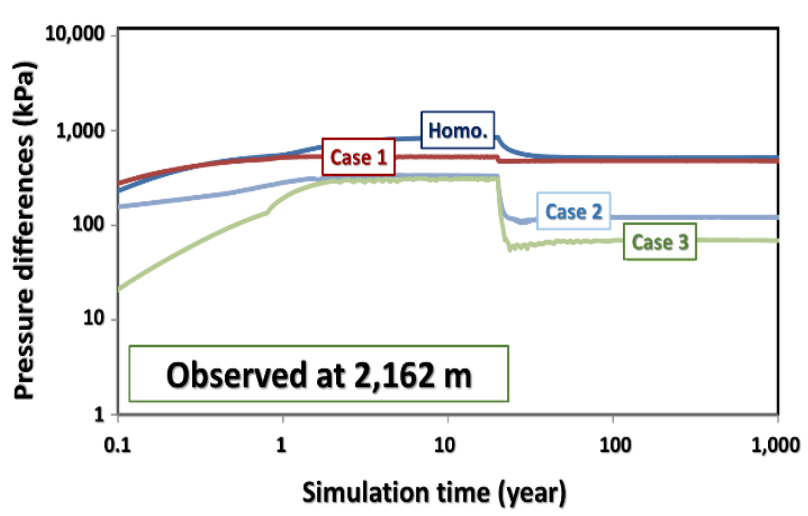

(a) Case 1 Case 3

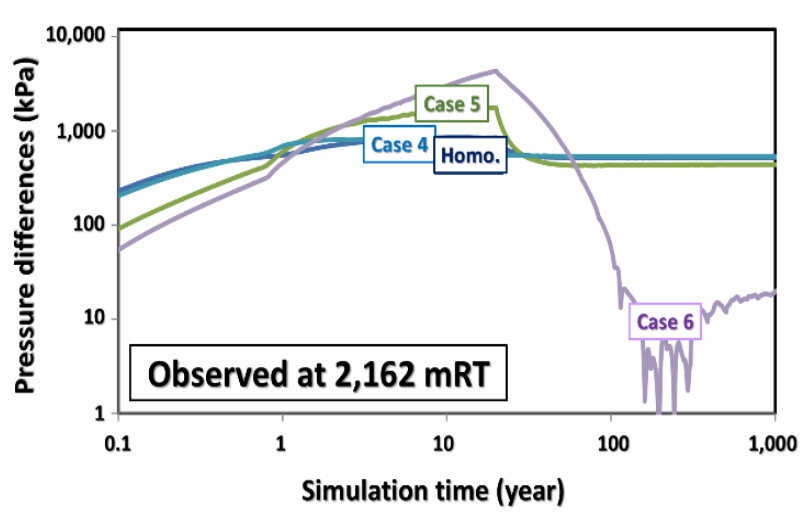

(b) Case 4 Case 6

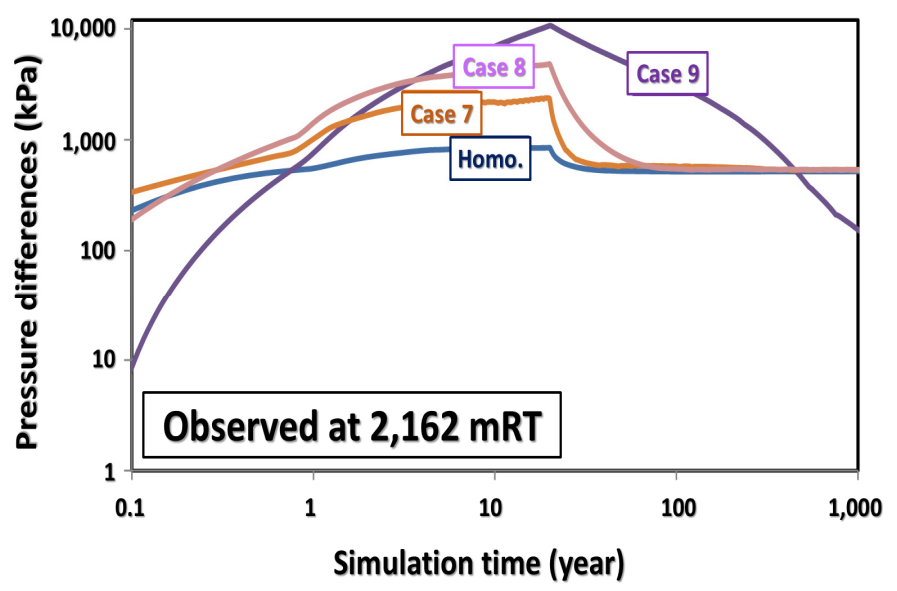

(c) Case 7 Case 9

Fig. 10 Overview of induced pressures calculated from the nine scenario cases for heterogeneous model.

\section{Conclusions}

The geological carbon sequestration model within Tai-Hsi Basin around the western coast in Middle Taiwan is established, based on existing seismic survey data and newly completed 3,000 $\mathrm{m}$ pilot drilling and coring data. Deep saline aquifer beneath an area of interest which characterized by alternations of sandstone, siltstone and mudstone (or shale) is concluded and suitable for a development. An intra-formation seal mechanism can be recognized for developing a three deep-seated reservoirs within the basin named as R-1, R-2 and R-3, respectively, with a total effective storage capacity around $13.7 \mathrm{Gt} \mathrm{CO}_{2}$.

The intra-formation seal accompanied by multilayered cap rock system is expected and capable of ensuring the safety and security of $\mathrm{CO}_{2}$ storage. Scenario analysis considering homogeneous and heterogeneous models was carried out to check the MHMD validity corresponding to realistic injection scenarios.

In the heterogeneous model case studies, the range of input parameters of porosity (20\%-35\%) and permeability $(0.0001-1,000 \mathrm{mD})$, respectively for the sandstone (storage layers) and/or shale (seals) have been selected according to results of laboratory core test. Probabilistic study is necessary and had been conducted to check the uncertainly when the assumed nominal porosity and permeability parameters might be changed. With nine cases of uncertain scenario analysis, the migratory cases of the injected plume for the heterogeneous model were carried out and regarded as quite realistic scenarios for the storage in the candidate deep saline aquifer, compared to that of homogeneous model.

Both of the corresponding MHMD of injected $\mathrm{CO}_{2}$ 
plume in the R-2 storage reservoir, and induced pressures at critical monitoring points above the injection zone had been calculated for possible nine scenarios. As a result, the intra-formation shale baffles had been proven to be capable of playing a vital role for ensuring the safe carbon storage operation within R-2 of Tai-Hsi Basin within a depth range in between 2,100 $\mathrm{mRT}$ and 2,500 $\mathrm{mRT}$.

Due to still lack of enough scientific evidences to validate real safety of cap rock system associated with intra-formational seal mechanism, an on-site pilot scale injection test and more extensive geo-risk scenario evaluations are strongly recommended prior to the decision of large scale sequestration design and operation in the candidate site.

\section{References}

[1] IEA Greenhouse Gas R\&D Programme. 2009. CCS SITE CHARACTERISATION CRITERIA: Site Selection Criteria for Ensuring the Safety and Security of $\mathrm{CO}_{2}$ Storage. Technical Study report No. 2009/10.

[2] Sinotech Engineering Consultants, Inc. 2011. Investigation, Pilot Planning and Research of Preferred Test Site for Carbon Geo-Sequestration. Research report submitted to Taiwan Power Company by Sinotech Engineering Consultants, Inc.

[3] Yu, C. W., Chen, S., Shao, K. S., Chiao, C. H., Hwang, L. T., and Chen. J. L. 2011. "Development of CCS Technology for Coal-Fired Power Plant in Taiwan." Energy Procedia 4 (April): 4806-13.

[4] Sinotech Engineering Consultants, Inc. 2011. Development a Two-Phase Test Facility. Research report submitted to Taiwan Power Company by Sinotech Engineering Consultants, Inc.

[5] Yu, C. W., Ko, W. C., Chiao, C. H., Hwang, L. T., and Yang, M. W. 2013. "Planning a Pilot Injection Test for a 3,000 m Deep Saline Aquifer in a Preferred Carbon Sequestration Site.” Energy Procedia 37 (August): 4960-7.

[6] Sinotech Engineering Consultants, Inc. 2014.
Investigation, on-site Investigation and Planning for a Pilot Test Program in a Preferred Carbon Sequestration Reservoir (Phase-1). Research report submitted to Taiwan Power Company by Sinotech Engineering Consultants, Inc.

[7] Yu, C. W., Chiao, C. H., Hwang, L. T., Yang, M. H., and Yang, M. W. 2014. "A Pilot 3,000 m Drilling for Characterizing a Candidate Deep Saline Aquifer in Western Taiwan." Energy Procedia 63 (December): 5071-82.

[8] IEA Greenhouse Gas R \& D Programme. 2011. Cap Rock Systems for $\mathrm{CO}_{2}$ Geological Storage. Report of IEA Greenhouse Gas R \& D Programme (IEAGHG).

[9] DNV GL (Det Norcke Veritas, Germanischer Lloyd). 2012. "DNV-RP-J203, Geological Storage of Carbon Dioxide and DNV-DSS-402 Qualification Management for Geological Storage of $\mathrm{CO}_{2}$." DNV-GL.

[10] Lin, T., Watts, A. B., and Hesselbo, S. P. 2003. "Cenozoic Stratigraphy and Subsidence History of the South China Sea Margin in the Taiwan Region." Basin Research 15 (4): 453-78.

[11] CO2CRC ( $\mathrm{CO}_{2}$ Cooperative Research Centres). 2011. "Carbon Capture and Storage Workshop." Carbon Capture \& Storage Workshop-August 13, 2011, Taipei.

[12] Daniel, R. F. 2006. Carbon Dioxide Seal Capacity Study. CO2CRC report No. RPT05-0039, Appendix 10.6.5 of report No. RPT05-0225.

[13] Gibson-Poole, C. M., Svendsen, L., Ennis-King, J., Watson, M. N., Daniel, R. F., and Rigg, A. J. 2009. "Understanding Stratigraphic Heterogeneous: A Methodology to Maximize the Efficiency of the Geological Storage of $\mathrm{CO}_{2}$." In Carbon Dioxide Sequestration in Geological Media-State of the Science, AAPG Studies in Geology, edited by Grobe, M., Pashin, J. C., and Dodge, R. I. Tulsa: The American Association of Petroleum Geologists, 347-64.

[14] Kameya, H., Ono, M., Takeshima, J., Azuma, H., Hiramatsu, S., and Ohmukai, N. 2011. "Evaluation for the Capillary-Sealing Efficiency of the Fine-Grained Sediments in Japan." Energy Procedia 4 (April): 5146-53.

[15] Pruess, K. 2005. $\mathrm{ECO}_{2} \mathrm{~N}$ : A TOUGH2 Fluid Property Module for Mixtures of Water, $\mathrm{NaCl}$, and $\mathrm{CO}_{2}$. Technical report LBNL-57952. 